\title{
Fraturas: origem e tratamentos
}

\author{
Gustavo da Rocha Velloso ${ }^{1}$
}

RESUMO - As fraturas representam uma fadiga de estrutura óssea. O estudo dos conceitos básicos sobre a organização do tecido ósseo, o mecanismo indutor das fraturas e o processo de consolidação são temas importantes da moderna traumatologia. Alterações estruturais nos ossos ocorrem em decorrência de complexo sistema de forças deformadoras. As lesões podem ocasionar alterações em diferentes tecidos ósseos. O tratamento das fraturas é usualmente realizado pela fixação interna e externa, mas experimentos modernos apontam para que o processo biológico de reparação das fraturas seja melhor do que a fixação metálica.

Palavras-chave: fraturas, origem, tratamento.

\section{Fractures: origins and treatments}

\begin{abstract}
Fractures are represented by a a failure of the bone architecture. The study of basic concepts of organization of bone tissue, inductor mechanism of fractures and bone healing are extremely important in modern traumatology. Structural changes of bone happen due to a complex system of forces. Biologic lesion of bone tissue can alter many related tissues. Treatment of fractures is usually done by internal and external fixation, but modern experiments are pointing that a better treatment is link to the biological process of bone healing.
\end{abstract}

Key words: fractures, origin, treatment.

${ }^{1}$ Professor da disciplina de Ortopedia da Faculdade de Ciências da Saúde do Centro Universitário de Brasília

-UniCEUBe daFaculdade de Medicina daUnB.E-mail: grvelloso@terra.com.br

Univ. Ci. Saúde, Brasília, v. 3, n. 2, p. 297-301, jul./dez. 2005 
As fraturas são definidas como a perda da solução de continuidade do tecido ósseo ou também como o resultado de uma fadiga da estrutura de um osso. São capazes de causar alterações funcionais temporais e ou permanentes e, na terceira idade, contribuem para aumentar os índices de mortalidade. Neste texto, apresentaremos a revisão dos conceitos básicos sobre a organização do tecido ósseo, o mecanismo indutor das fraturas, o processo de reparação óssea e os métodos de tratamento das fraturas.

O tecido ósseo, que dá forma e resistência aos nossos ossos, é um tipo de especial de tecido conjuntivo e constitui a maior parte do esqueleto humano. A despeito de ser fisicamente rígido, é uma estrutura dinâmica e ágil, sujeita a alterações locais e metabólicas. É considerado estrutura ímpar, pois, durante a formação, retém a capacidade de alterar sua forma e estrutura, em resposta a mudanças do meio em que se insere ${ }^{1}$.

Os ossos, segundo Gamble (1988), podem ser estudados de três maneiras diferentes: como material, como tecido ou como órgão. Considerado como material, o osso é visto como um composto resistente à compressão, semelhante a uma estrutura de concreto com sua estrutura metálica representada pelas fibras colágenas e o cimento por sua rica matriz mineral. O osso, quando visto como tecido, consiste em células vivas embebidas por rica matriz vascular e mineralizada. O seu conteúdo sólido representa noventa e dois por cento de sua massa total, sendo os oito por cento restantes compostos de água. As fibras colágenas são a estrutura mais importante da matriz orgânica constituindo noventa e cinco por cento do seu conteúdo total. Os três tipos de células ósseas, o osteoblasto, o osteócito e o osteoclasto, representam somente três por cento de sua massa total. Ao estudarmos os ossos como órgãos, podemos verificar, em sua estrutura, a presença de tecidos, como o cartilaginoso, o nervoso, o conjuntivo, o adiposo, o vascular e o hematopoiético.

As importantes propriedades do osso são a rigidez, a leveza e a capacidade de suportar deformações que existem em decorrência da organização estrutural em lâminas tanto na porção cortical como na trabecular. A forma tubular dos ossos longos, com estrutura radial de sua massa e o reforço interno representado pela arquitetura trabecular, confere-lhes singular e resistente estrutura.

Os ossos apresentam mudanças estruturais nas diferentes fases de nossa vida, sendo pouco densos, flexíveis e bastante hematopoiéticos em jovens e muito rígidos, porosos e com medula fibrosa e gordurosa nos idosos. A morfologia de cada osso é determinada pela carga genética de cada indivíduo, e o crescimento do esqueleto, influenciado por alterações físicas e biológicas, tais como, o estado nutricional, a ação muscular e a carga axial suportada. 
Fraturas: origem e tratamento

\section{A fratura}

O termo fratura tem origem na palavra latina "fractura", que significa quebrar. O tecido ósseo está exposto a fatores capazes de gerar cargas e alterar as suas características estruturais e biológicas. O estudo da mecânica da falência óssea ou das fraturas é complexo, mas é importante que seus fundamentos sejam apresentados para melhor compreensão. Do ponto de vista mecânico, a fratura é uma perda de solução de continuidade do tecido ósseo normal, resultante de carga excessiva que ultrapassa a capacidade de resistência do osso.

O estudo das forças e da energia capazes de produzir uma fratura permite a análise dos fatores causais e a elaboração de classificações para os vários tipos de fratura. O corpo humano, para executar as suas atividades diárias de lazer, sociais, esportivas ou profissionais, impõe aos ossos um conjunto de forças, nas quais estão incluídas a da gravidade, a de impacto, a músculo-tendinosa, a ligamentar e a compressiva. Assim, é importante, para estabelecermos o diagnóstico e compreendermos como a fratura ocorreu, a avaliação da magnitude da força aplicada ao osso, a localização, a direção, o tempo de atuação e o ritmo com que foi aplicada à estrutura óssea. É raro identificarmos força única responsável por uma fratura, por isso usamos o conceito de força de maior prevalência agindo em um sistema. Forças de impacto contra um segmento ósseo, quando ocorrem, são distribuídas rapidamente em toda a superfície. Entretanto, o princípio mecânico das lesões sugere que, à medida que a área de aplicação da força aumenta, a probabilidade de ocorrer uma lesão focal diminui, razão pela qual as forças de grande magnitude, quando aplicadas a um membro superior ou inferior, podem não causar fraturas expressivas, pois têm a energia absorvida em uma área não localizada.

O equilíbrio do segmento ósseo ou de uma articulação é definido como o balanceamento das forças que atuam na região. Assim, a falha óssea irá ocorrer quando a carga aplicada a determinado segmento exceder a capacidade de sustentação. A razão entre a capacidade de sustentação de cargas e as forças que atuam sobre o osso é denominada fator de segurança. A razão inversa é denominada fator de risco da fratura. É importante salientar que ambos os fatores variam de acordo com o tipo, a localização, a forma e a qualidade biológica de cada osso do esqueleto. No fêmur, por exemplo, os idosos são acometidos de fraturas com incidência maior que os jovens, e as crianças sofrem mais fraturas do antebraço do que os adultos.

Do ponto de vista mecânico, o que acontece quando ocorre uma fratura é a dissipação de um sistema de forças em um segmento ósseo. Por outro lado, do ponto de vista biológico, a dissipação de forças poderá promover profundas

Univ. Ci. Saúde, Brasília, v. 3, n. 2, p. 297-301, jul./dez. 2005 
alterações celulares, vasculares, neurológicas, hematopoiéticas e musculares, entre outras.

Usualmente, as fraturas são descritas e classificadas em grupos de acordo com o cenário do dano biológico apresentado. Desta forma, produzidas por forças de baixo impacto são denominadas incompletas nos adultos e, nas crianças, recebem a denominação de subperiostais. $\mathrm{O}$ aumento das forças de deformação óssea pode acarretar fraturas completas sem que haja exteriorização dos fragmentos, as chamadas fraturas fechadas, ou, caso contrário, recebem a denominação de fraturas abertas. No caso de uma fratura situar-se próxima ou na superfície articular, será denominada fratura articular, constituindo exemplo de maior dano tecidual. Classificamos, também, as fraturas de acordo com a posição do osso ao receber a carga de forças e a sua intensidade, sendo exemplos as fraturas oblíquas, transversais, segmentares e cominutivas, constituídas por múltiplos fragmentos ósseos. As inúmeras e detalhadas classificações das fraturas levaram Lewis (2004) a solicitar que sejam orientadas no sentido de fornecer bases para a comunicação mais fácil, aumentando o conhecimento das condições patológicas causadoras das fraturas e permitindo avaliação dos resultados práticos dos tratamentos utilizados.

\section{$O$ tratamento}

O tratamento dos tipos de fraturas inicia-se independentemente do método utilizado, logo após a fratura ocorrer e é expresso pelo processo de consolidação dos ossos. O processo é complexo, ainda não completamente elucidado. O seu estudo foi sistematizado por McKibbin (1984), que representa a resposta das células osteoprecursoras situadas no periósteo e no endósteo do osso a fatores ativadores liberados quando da fratura. Kenwrigth (2000) descreve as condições necessárias para que o processo seja realizado sem anormalidade. As mais importantes são: boa vascularização, bom estoque de células ósseas, ausência de infecção, boa aposição dos fragmentos e ausência de mobilidade excessiva do foco de fratura.

Quatro fases distintas são comumente descritas no processo de reparação das fraturas. A primeira envolve a estabilização interfragmentária com a formação de um calo periostal e endostal, baseado no processo de diferenciação da fibrocartilagem do foco da fratura, e é conhecido como fase do calo ósseo mole. A segunda é representada pela fase de restauração do foco de fratura quando ocorre reorganização celular intensa e a formação de novo arcabouço ósseo, sendo denominada fase do calo duro. A terceira caracteriza-se pela substituição das áreas de necrose por osso novo feita pelo sistema haversiano do osso compacto. $\mathrm{Na}$ última fase, ocorre a remodelagem do osso com a reconstrução de sua forma e arquitetura, visando à adaptação funcional das forças que agem sobre o tecido 
ósseo local. O final do processo corresponde à união óssea e representa, do ponto de vista tecidual, a recomposição completa da lesão do osso.

A fixação interna do osso por meio de grande diversidade de placas, parafusos, fios metálicos, grampos e hastes tem o objetivo de promover a estabilização dos fragmentos da fratura, diminuir o período de repouso muscular, facilitar a vascularização do local do trauma ósseo e auxiliar o alinhamento ósseo. $\mathrm{O}$ uso de metais na fixação dos ossos atende aos princípios da biocompatibilidade, de não ser imunogênico, atóxico, e resistência a tração, compressão e erosão. No entanto, a procura por material que tenha características mais próximas às do tecido ósseo ainda continua e deve persistir por longo período, pois a fadiga do material e sua conseqüente diminuição de propriedades tem sido o calcanhar de Aquiles da síntese óssea.

O contínuo aprendizado adquirido no tratamento dos diversos tipos de lesões da estrutura óssea ao longo da prática ortopédica tem demonstrado o quanto é importante o estudo da histologia e da fisiologia óssea. O tratamento biológico das fraturas, auxiliado pelos constantes avanços da biologia molecular, é, talvez, o caminho mais breve e seguro a ser traçado na prática da traumatologia óssea, pois tem apresentado resultados promissores e menos invasivos ao tecido ósseo ${ }^{2}$.

\section{Referências}

DRAGOO, L. et al .Tissue-engineered cartilage and bone using stem cells from infrapatellar fat pads. In: J.Bone Joint Surg.85B:740-747, 2003.

GAMBLE, J.; RAVEN, G (ed). The musculoskeletal system. New York,1988.178p.

KENWRIGTH, J. Fracture after distraction osteogenesis. In: J. Bone Joint Surg. 82B:659$665,2000$.

LEWIS,G. The classification of fractures. In: Current Othopaedics.14:223-224, 2000.

MCKIBBIN, B. The biology of fracture healing in long bones. In: J. Bone Joint Surg.,60B:150-162,1978.

VELLOSO,G.R. The cellular control of morphogenesis in skeletal development. Institute of Orthopaedics, Londres, 1990. 40p. Dissertação de Mestrado. 
Envie suas publicações para o Conselho Editorial da revista Universitas - Ciências da Saúde.

Endereço para envio: SEPN 707/907, Campus do UniCEUB

70790-075 Brasília-DF

Fone: (61) 3340-1397

universitas.saude@uniceub.br

Verifique as normas de submissão no final deste número 